Running head: Expertise in burglars

Understanding expertise in burglars: from pre-conscious scanning to action and beyond.

To appear in Aggression and Violent Behaviour, special edition on expertise in offenders

\author{
Claire Nee \\ Department of Psychology \\ University of Portsmouth \\ King Henry Building \\ King Henry $1^{\text {st }}$ St \\ Portsmouth \\ P012DY \\ U.K.
}

Email: claire.nee@port.ac.uk 


\begin{abstract}
This article aims to review empirical research on residential burglary over the last three to four decades and relate these findings to a model of 'dysfunctional expertise' (Nee \& Ward, this issue) that is rooted in mainstream cognitive psychology. It begins with a description of the elements of expertise that might fit in to this model and then traces the offender's decision-chain, using the model as an explanatory tool. Studies have shed light on: the automatic and habitual appraisal of the criminogenic environment during the daily, routine activities of the burglar and his journey to crime; accruing situational awareness and automatic recognition of cues signifying vulnerable properties during target selection; and speedy deployment of offending scripts based on tried and tested methods when entering and carrying out the crime. The review highlights how little is known about decisions, reflections and emotions after the crime. Aspects of the model that require development through further research, as well as the value of using the model for crime prevention purposes, are discussed.
\end{abstract}

Keywords: burglary; expertise; automaticity; schema; crime prevention 


\section{Aims of this article}

The aim of this article is to gain a greater understanding of the specific cognitive processes that drive the development of expertise in this type of offending behavior in the days and hours surrounding the crime. Although residential burglary rates have fallen by about a quarter internationally in the last decade (Tseloni, Mailley, Farrell \& Tilley, 2010) it is still clearly a prevalent, costly and destructive crime (e.g. 700,000 incidents a year in the UK (Crime Survey of England \& Wales (CSEW), 2013) and more than 3.7 million incidents per year in the U.S. (Truman, Langton \& Planty, 2013)). Burglary is usually the crime that the general public worries most about (Bullock, Chowdhury \& Hoolings, 2009; Warr, 2000) because it is perceived as a relatively frequent crime and victims of burglary can suffer similar levels of trauma and distress as victims of robbery and assault (Lurigio, 1987). Further, the clearance rate for reported burglary is generally very poor (e.g. around $13 \%$ in the US (Federal Bureau of Investigation, 2009) and 17\% in England \& Wales (Smith, Talyor \& Elkin, 2013)) indicating that many offenders remain active and at large in the community, some perhaps with greater proficiency than others. Much is still to be known then, about the thought processes and behavior that drive this crime and about ways to prevent it. This article will review what we have learnt about the goals, decision-making, skills and behavior of the burglar through observation, interview and experiments with the offenders themselves over more than three decades of research. Throughout the article, findings will be related to the model of 'dysfunctional expertise' outlined in Nee and Ward (this issue) in an attempt to strengthen our conceptualization of the issues, providing a basis for moving forward towards more effective crime prevention.

Over the decades, strands of complementary research on burglars' cognitions, behavior and decision-making have emerged, each study building on the last. With the offender firmly as 
the focus of attention in this work (Nee, 2010), this has lead to: increasingly sophisticated methodologies; research questions generated, explored and validated by the offenders themselves; and the creation of a considerable body of knowledge. Theoretical development, however, has been disparate with scholars augmenting both environmental/rational choice perspectives (e.g. Brantingham \& Brantingham, 2004; Cromwell, Olson \& Avary, 1992) and more macro-oriented social control and deterrence models (e.g. Jacques, Wright \& Allen, 2014; Wright \& Decker, 1994). The epistemological value of pulling together a dysfunctional expertise model of burglary would be to more clearly explain what we know about the proximate decisions and behavior of the burglar at the scene of the crime and also to set the scene for a more exacting enquiry of such issues in future research. While most closely aligned with situational perspectives, it should be a valuable complementary tool to social control models. The dysfunctional expertise approach to understanding the workings of the offender's mind in and around the scene of the crime, is based on decades of experimental research in the cognitive sciences. The latter work highlights the importance of processes that become unconscious and automatic over time through practice and recognition of trigger cues, alongside more deliberative, conscious decisions and behavior. To set the context for this article, our posited model includes four stages of decision-making that occur in the days, hours and minutes leading up to the commission of the crime and beyond, as follows:

1. Automatic, unintentional, pre-conscious appraisal of the environment that cannot be turned off

2. Superior, automatic recognition of the environmental, offense-related cues meaningfully related to the domain of expertise

3. The activation of complex cognitive schemas, built up through practice, allowing instantaneous, compensatory access to a rich number of exemplars and heuristics. This in turn will guide: 
4. Speedy responses to environmental cues that have worked in the past in the form of the playing out of behavioral scripts, allowing a relatively automatic commission of the act.

For a more detailed account in relation to how this model was derived, see Nee and Ward (this issue). The intention in the current article is to demonstrate how it can be used to more precisely capture and explain what we know about burglary and how it might prove useful in future research. Specifically, I hope to use the model to describe and explain processes from the beginning of the offense decision chain (some time away from the crime) to the end (post offence) in a more cohesive way. I will look in turn at research underpinning the scanning of the environment for 'criminogenic' cues that occurs in advance of and during target selection; the journey to crime; the process of target selection; target entry and commission of the crime; and the cognitive and emotional processes in the hours after the crime. The implications of using this model and future directions for research in order to validate its usefulness as an explanatory tool will then be discussed.

\section{Pre-conscious scanning of the environment}

The idea that burglars scan the environment as part of their routine, daily activities has been around almost as long as offender-based research on burglars has. Bennett and Wright (1984) were the first to coin the term 'searchers' (p.43). This group represented around half of the 117 experienced, convicted burglars in one of their studies.. The term 'searcher' signified that target choice was made at the scene of the crime, using previously learned environmental cues that indicated the vulnerability of the property. Typically, the initial decision to commit the burglary emerged some time before target choice and the 
commission of the crime, as a result of the need for funds, some days or hours before the crime. As a consequence the burglar then travelled to an environment/district thought to be favorable for burglary based on previous experience, and searched for a suitable target. A further $17 \%$ of Bennett and Wright's sample returned later to an already chosen 'vulnerable' residence noted during routine daily activities ( e.g. in the course of their employment, leisure activities etc.) using the same environmental cues (affluence, accessibility etc.) that their 'searcher' counterparts had used while searching for a target. If for some reason this $17 \%$ were deterred from entering their property of choice, they would search for another suitable one in the same location. Bennett \& Wright's work was exemplary in the sense that alongside interview methods, they also undertook a number of experiments. These elicited the offenders' free-response to visual cues in videos and photos to corroborate the apparent skill of the burglar in choosing targets. They did not use comparison groups however and their samples involved only incarcerated burglars as was criticized later (see Nee \& Taylor, 1988 and Wright \& Decker, 1994). Criticisms aside, they produced important evidence that the majority of experienced burglars undertook routine scanning of the environment for suitable targets in advance of the actual crime that is not opportunistic or wholly impulsive. In relation to Nee \& Ward's (this issue) model of expertise, their work suggests that the strength of the potential reward of burglary, linked to positive emotions in memory, will make some cues in the everyday environment more powerful and salient than others, affecting motivation and allowing the goal (of burglary) to be activated unconsciously (Chartrand \& Bargh, 2002). This underpins the superior-situational awareness that burglars (and other offenders) appear to possess, represented in Stages 1 and 2 of our model above. 
Even before Bennett \& Wright's landmark research, Shover's early ethnographic interviews addressing burglars' behavior and lifestyles in the USA pointed to the importance of offenders' appraisal of the environment in advance of committing an offense. In his 1973 study of 143 experienced burglars (mostly incarcerated though often not for burglary) Shover described the 'good burglar' who was technically competent, relatively successful and tended to specialize in burglary. His interviewees described 'scouting trips' in their free time - cruising around looking for potential targets based on value and vulnerability. A team of burglars would then visit a few times to assess their approach and the best time of day to approach the target.

On the basis of Bennett and Wright's work, Nee and, Taylor undertook a series of three studies in the Republic of Ireland in order to replicate or otherwise this seemingly superior knowledge and skill apparent in burglars' decision-making in the criminogenic environment. They improved on previous work by including comparison groups of potential 'novices' (householders) and did not rely on self-report methods only, by utilizing freeresponding experiments. In their interview study (Nee \& Taylor, 1988) and two experiments using maps and slides of residential areas (Taylor \& Nee, 1988; Nee \& Taylor, 2000), experienced burglars identified the environmental factors that influenced their decisions to offend. Three quarters of the Nee and Taylor samples fell into the 'searcher' category, making the initial decision to offend away from the eventual scene of the crime, for instrumental reasons (like Brantingham \& Brantingham, 1993; Maguire \& Bennett, 1982; Bennett \& Wright, 1984; and later, Cromwell, Olson \& Avary, 1991 and Hearndon \& Magill, 2004) to maintain an often expensive lifestyle ('life as party' as Shover (1996) describes it). Only five the sample of 50 described relief from boredom, impulsivity and enjoyment as the 
central underpinning motivation for their crimes. Similar to other samples (Bennett \& Wright, 1984; Maguire \& Bennett, 1982), a small number of participants demonstrated a more planned approach than the searchers, often initially picking their targets using environmental cues associated with lucrative burglaries, days in advance of the actual burglary and then watching the comings and goings of the occupants. Another method for more planned burglaries was to work on commission for receivers of stolen goods. While the goods were already identified, other cues (such as occupancy, access to the property and security features) rendering the property more or less easy to enter were used to decide when to actually undertake the burglary. It should be stressed that the 'searching' process described above is a typical approach, but there is also evidence from later studies that many 'searcher' burglars work on tip-offs from time to time, using a more planned approach (Nee \& Meenaghan, 2006), especially as expertise accrues (Clare, 2011). Also in line with Clare (2011) these early studies show evidence of the continuum of expertise found in any domain (Chi, 2006; Nee \& Ward, this issue), with each sample of burglars including small numbers of more opportunist offenders at the less experienced end, more proficient and skilled 'searchers' dominating samples and those with a planned approach on the top end of the spectrum. It also concurs with Ericsson, Krampe \& Tesch-Romer (1993) that not all of those with experience in a domain will reach the highest levels of expertise.

Somewhat disappointingly, despite the ground-breaking work of Bennett and Wright and researchers who subsequently supported their findings regarding the sequential decision-making process of burglars, many scholars working in the field have continued to restrict their discussions of these issues to a dichotomous 'planned versus spontaneous' analysis of the thinking and behavior of offenders (e.g. Cromwell et al, 1991). In fact, as the 
findings above and below suggest, there is good evidence that the reality is somewhere in between, and the process is more complex than this dichotomy suggests. The planned versus spontaneous dichotomy may seem analogous to the 'deliberative' versus 'automatic' dichotomy in decision-making. However, research on the journey between unconscious and conscious thought suggests a more intricate, multi-level and graded process in which automatic and deliberative thought may be in conflict ( see Nee \& Ward, this issue for more detail). In later studies with convicted burglars in the UK (Nee \& Meenaghan, 2006), Australia (Goodwin, 2007), and active, unconvicted offenders in the United States (Cromwell et al, 1991; Wright \& Decker; 1994), this pattern regarding continuums of planning and expertise has been replicated. Cromwell et al's (1991) study of active burglars in Texas is replete with examples of heuristic decision-making based on responses to environmental cues, in alignment with the superior situational awareness characteristic of experts (Ericsson \& Kintsch, 1995; Nee \& Ward, this issue). Their 'journeyman' burglar (75\% of their sample of 30) 'searches out and creates opportunities' (p.50) based on systematic recognition of environmental cues signifying gain and low risk. The authors note similarities with Shover's (1973) 'good burglar', Bennett \&Wright's (1984) 'searcher', and Rengert \& Wasilchick's (1985) 'suburban burglar' typology. Cromwell et al (1991) first interviewed their participants away from the scene of the crime and later re-interviewed them at a recent target, noting that their sample appeared more reactive to cues and less 'rational' at the scene of the crime than during the initial interview. While Cromwell et al (1991) use this finding to criticize prison interviews with convicted offenders as 'rational reconstructions' with limited validity, one would expect cue appraisal and processing at the actual scene of the crime to be more automatic and less deliberative (Nee \& Ward, this issue) than in an interview, and the findings from both methods concur rather than contradict one another. Importantly, in 
all of these studies, experienced burglars describe scanning and routinely appraising the environment for burglary opportunities, in the days and hours away from the eventual scene of the crime.

Later studies also support this idea. In Wright and Decker's (1994) study of 105 active burglars in St Louis Missouri, their participants described a process of 'half looking' (p.80) for targets while going about their daily business and remaining attuned to potential targets at all times, by perhaps walking home a different way and 'scoping' (p.81) potential houses to burgle. They describe themselves as neither deliberately looking for targets nor ever completely turning this process off. Finally, Nee and Meenaghan's (2006) interview study noted that three quarters of their incarcerated sample of burglars $(n=50)$ fell into the searcher category (demonstrating automatic situational awareness) when choosing targets, the remainder being either more disorganized or highly planned in their approach.

Methodologically, ethnographic interviewing with unconvicted, active offenders at the scene of recent crimes (Cromwell et al, 1991; Wright \& Decker, 1994) represented an ambitious and valuable step forward in terms of the ecological validity of the visual stimuli presented and the samples used. It built on and extended our knowledge considerably, especially in terms of behavior inside the target. It was still subject to the limitations of interviewing however, and one could argue that simulations (especially given recent technology) better facilitate immersion in the environment, resulting in observable behavior rather than verbalizations (Nee 2010).

The findings reviewed above fit closely with two complementary approaches to understanding offender decision-making and behavior which emphasize the environment in which crime occurs. Firstly, according to the 'routine activities approach' (Cohen \& Felson, 
1979; Felson \& Boba, 2010; Osgood, Wayne, Wilson, Bachman, O'Malley \& Johnston, 1996)

daily activities of law abiding citizens create opportunities for illegitimate activities. A criminogenic opportunity requires a motivated offender (who may need money in the next 24 hours and who has recognized vulnerability cues during his own routine daily activities); an opportunity (for example, a residence that is empty during the day or. during a school run); and the absence of a capable guardian (e.g. householder). Statistical analysis of actual crime locations supports this idea of criminal 'hot spots' of opportunity emerging (Sherman, Gartin \& Buerger, 1989). By interviewing convicted burglars, Rengert and Wasilchick (1985) found a direct relationship in their sample between target choice and participants' journey to work. Additionally, a considerable body of work has been conducted by the Brantinghams in relation to a 'pattern theory of crime' (see Brantingham \& Brantingham, 2004 for a good overview). Their work has been more focused on the spatial and temporal patterning of crime and how architectural considerations could affect it and could be criticized for not taking into account the offender's perspective. However, their theorizing has usefully combined both these perspectives, arriving at a position quite early on in the history of offending behavior research that sits very comfortably with our model of dysfunctional expertise. In the early 1990's the Brantingham's postulated theories concerning offenders' use of cognitive 'templates' that are utilized in the sequence of decisions that result in the eventual crime, some of which are conscious and some of which are not, but that are nevertheless predictable. They describe the importance of the offender's 'state of readiness to commit crime', which requires enough knowledge to perceive and act upon an opportunity when it is discovered in a 'known activity area' or 'awareness space' (indicating superior recognition of trigger cues). These are all terms and concepts that fit with accrued expertise and tacit knowledge that is activated in familiar environments. 
Perhaps more crucially, the above empirical findings in relation to routine appraisal of the environment, from diverse samples of burglars across the years, could relatively easily be accounted for by the speedy, automatic, pre-conscious processing evident in experts (Ericsson, 2006). They provide some evidence for the first two stages of our model of dysfunctional expertise (Nee \& Ward, 2015, this issue), including automatic, preconscious appraisal of the environment resulting in instantaneous recognition of offenserelated cues. By drawing on decades of robust experimental research (see Nee \& Ward, this issue) our model of expertise can furnish us with a more precise and exacting understanding and interpretation of processes leading up to the commission of the crime, one with which we can have some confidence, given its evidence base.

In forensic psychology and criminology, very little systematic attention has been paid to this important phase of decision-making in the offense chain, which may occur days before the offense, but all of the findings above support it implicitly. Given what we know about human information processing (see Nee $\&$ Ward, this issue) it is highly likely that the routine, habitual scanning phase of the decision process described in so many studies, is mostly automatic and unconscious (why would burglars differ from the rest of the human race in terms of experienced decision-making?). However, robust experimental work with experienced offenders and a variety of comparison groups needs to be undertaken in order validate this idea and explore it in depth.

\section{Actual target selection}

Work on the selection of targets by residential burglars is the area that is most developed in terms of the decision-making processes proximate to the commission of the crime. Research specifically focused on this phenomenon began in the UK in the 1980's 
(Maguire \& Bennett, 1982) as a result of several exploratory US studies. These studies alluded to the use of environmental cues indicating such things as affluence and occupancy in target selection (Reppetto, 1974; Scarr, 1973; Shover, 1973; Waller \& Okihiro, 1978). This early work was also scaffolded by an emerging interest in the 1970's in the environment in which crime occurred from architects and criminologists; what has come to be known as 'environmental criminology' (e.g. Brantingham \& Brantingham, 1975a, 1975b, 1991, 1993; 2004; Mayhew, Clarke, Sturman \& Hough, 1976; Newman, 1972). Together, these complementary strands of research continued into the 1980 s (e.g. Heal \& Laycock, 1986; Clarke \& Hope, 1984) and resulted in a new view of the offender as less impulsive and more governed by a 'bounded rationality' (Cornish \& Clarke, 1986), using heuristics based on decision and actions that had worked in the past.

As noted above, numerous studies depicted a typical burglar as someone who generally makes the initial decision to undertake a burglary away from the eventual scene of the crime and then embarks on a series of decisions (or 'decision-chain') until the crime has been committed. We will trace these steps as the burglar approaches the scene of the crime.

\subsection{The journey to crime}

Numerous studies indicate that, in general, the burglar is likely to approach a residential area that he is familiar with and therefore is likely to live relatively close to (Bernasco \& Luykx, 2003; Bernasco \& Nieuwbeerta, 2005; Brantingham \& Brantingham, 1975a, 1993; Elffers et al, 2008; Maguire \& Bennett, 1982; Rengert \& Wasilchick, 2000; Sherman, Gartin \& Buerger, 1989; Waller \& Okihiro, 1978). During his daily (non-criminal) activities the offender will have noted, for instance, the increased market value of a 
particular locale coupled with vulnerability cues. His superior situational awareness and selective attention for cues associated with lucrative burglaries will have automatically and unconsciously drawn his attention to these cues.

Alternately, the offender may make his way to an area that he has undertaken burglaries in before, knowing that the general physical environment is likely to present lucrative and accessible opportunities. In either case, on arrival at the potential neighborhood, he will appraise the current configuration of cues in order to pick the most favorable target. Another strategy might be that, on his way to a potential break-in location, he may become aware of a new locale that partially meets his needs and is worth further exploration. Exploration of new areas will be somewhat more risky and the offender will take care that he does not look out of place and feels comfortable with the level of passers-by and householders who he is visible to in order to 'scout' the area (Cromwell et al, 1991; Rengert \& Wasilchick, 2000; Waller \& Okihiro, 1978). This is delicate balance. On the one hand, we have seen (see Nee \& Ward, 2015, this issue) that cognitive schemas that become over-burdened with new, unfamiliar information, cease to function effectively (Woollett \& Maguire, 2010). On the other hand, we have evidence from Clare's (2011) study of expert versus novice burglars that those with greater expertise have greater self-efficacy and feel more confident in exploring partially or wholly unfamiliar territories/properties further away from home than their less experienced counterparts (Clare, 2011). As a result of their increasingly rich and interconnected cognitive schemas, they can make useful inferences from even small amounts of partially familiar information (Duckworth, Bargh, Garcia \& Chaiken, 2002; Gilovich, 1981). 
This also fits with the increased confidence (often over-confidence) seen in experts in general (e.g. Chi, 2006) - which might be something that can be exploited for crime prevention reasons. It goes without saying that potential visibility from other properties, neighbors and passers-by continue to be monitored throughout the process of choosing of the target, upon entry and upon exit.

It is important at this stage to acknowledge the influence of internal as well as external cues on decision-making as the offender approaches the scene of the crime. These might include the effects of hunger, thirst, fatigue, stress, excitement, physical illness, mental illness, substance misuse or anger and similarly may be outside the offender's fully conscious awareness. These effects have rarely, if ever, been studied in depth. Many of the earlier studies of burglars and their actions examined their emotions leading up to and during the burglary and attempted to clarify to what extent these contributed to the decision to offend. While the instrumental need for money was overwhelmingly cited as the primary motivator for an offence, many studies highlighted the role of a heightened sense of physiological arousal leading up to, during and after the crime (Cromwell et al, 1991; Reppetto, 1974; Shover, 1996; Taylor \& Nee, 1988; Wright \& Decker, 1994). To what extent heightened emotions are experienced as positive or negative, or are part of the cause or the effect of behavior, needs elucidating if we are to understand better how to intervene with the chain of decisions to offend in the days, hours and minutes before the crime. Although burglary is primarily an instrumental crime, it would be unwise and naive to disregard the integral part that emotion plays in cognitive processes (Van Gelder, Elffers, Nagin \& Reynald, 2014; Ward \& Nee, 2009). Its impact will be even more important in expressive crimes, such as acts of violence or sexual offending, and from a neuro-physiological point of view, it is 
interesting that areas of the amygdala closely associated with impulsivity are also correlated with emotional memory (Hamman, 2001; Nee \& loannou, forthcoming).

To return to the journey to crime, as suggested above, burglars rarely have a particular target in mind when they reach the general location of the potential crime, such as a row of houses or housing estate (Bennett \& Wright, 1984; Brantingham \& Brantingham, 2004; Maguire \& Bennett, 1982; Nee \& Meenaghan, 2006; Nee \& Taylor, 2000) and that this is even less likely as expertise increases (Clare, 2011). Even if a particular target had originally aroused their attention in the preceding days, they may choose another having arrived in the area, which signifies a better outcome at that point in time. Experiments comparing experienced burglars with ordinary non-offenders (novices) on how they check out a criminogenic locality (the pathways and access around targets) indicate that burglars use significantly fewer, cleaner and more systematic routes than their novice counterparts and do so in a significantly shorter amount of time (Nee \& Taylor, 1988; 2000). There is an abundance of information about what aspects of the environment the burglar interprets as attractive or a deterrent when discriminating between potential targets. One of the original aims of Nee and Taylor's work was to examine whether particular cues, or classes of cues had more influence on decision-making at the scene of the crime than others and the answer was a resounding no. Not surprisingly, the process is complex and dynamic in which cues combine and mediate the effects of each other (suggesting dense, inter-related schemas on the part of the appraiser- see Nee \& Ward, 2015, this issue) and the significance of different cues can change on an hourly basis (Nee \& Taylor, 1988, 2000).

During interviews, burglars tend to spend more time talking about cues associated with the level of pay-off (wealth cues, Nee \& Meenaghan, 2006; Nee \& Taylor, 2000) 
coupled with architectural, topographical and access (layout cues, Nee \& Meenaghan, 2006; Nee \& Taylor, 2000). This is in contrast to cues indicating occupancy and security. This might suggest that that these cues are more salient in the process, carrying more weight due to a stronger association with reward in memory. It may also suggest that they are processed more speedily. That said, in Nee \& Taylor's (2000) third study which comprised a complex and relatively realistic simulated residential environment, the unique combination of cues that each of the five houses presented appeared to be processed extremely quickly (significantly faster than novice householders) as it came into the burglar's view. No one 'type' of cue held more salience and cues seemed to have an interactive and mediating effect on each other. More rigorous testing of these ideas, using information-processing experimental methodologies may help elucidate whether some cue types are more important in this process, but it remains to be seen whether this would help us regarding crime prevention in the real world. The Nee \& Taylor (2000) study above suggested that the process is extremely fast and dynamic, with multiple cues being processed in very quick succession. It suggested that combination rather than the type of cue was more important, though this needs replicating with larger samples and more precise measures. In any case, the environment is rich and many cues signify several things at once. For example, vegetational cover in a garden may improve the perceived overall value of the property, but will certainly also reduce its security, allowing the burglar to hide and appraise the potential target more thoroughly for access and occupancy without being seen. Similarly, side and rear access often indicates a larger, more valuable property, but also increases the opportunity for entry at both of these points. It is useful to note though, that Homel, Macintyre and Wortley (2014) showed that the number of cues used to decide on a target decreased with burglary experience (indicating richer schemas). This concurs with work by 
Garcia-Retamero and Dhami (2009) and Snook, Dhami and Kavanagh (2011) showing that, in comparison to non-offending participants, experienced burglars used more frugal, compensatory strategies to choose their targets, suggesting that one salient cue per property (called 'take-the-best' strategy) may be central to decision-making. This was in contrast to the time-sapping, analytical processes used by the novices. It would be good to replicate these findings in more naturalistic, simulated criminogenic environments (photographs were used) but they nevertheless provide more support for the idea that the experienced burglar has speedy access to rich, schematic knowledge as he reaches the scene of the crime and chooses a target.

3.2 Target selection at the scene of the potential crime: How much will I make and can I get access to this target?

Environmental signals denoting relative size and decor, in relation to surrounding properties are central cues to this aspect of the evaluation. Numerous studies from around the world with incarcerated and active burglars (Bennett \& Wright, 1984; Cromwell et al, 1991; Goodwin, 2007; Maguire \& Bennett, 1982; Logie, Wright \& Decker, 1992; Nee \& Meenaghan, 2006; Nee \& Taylor, 2000; Palmer, Holmes \& Hollin, 2002; Rengert \& Wasilchick, 1985; Wright \& Decker, 1994; Wright \& Logie, 1988; Wright, Logie \& Decker, 1995) often in comparison to 'novice' populations such as householders, students, police officers and sometimes other (non-burgling) offenders indicate superior recognition of cues signifying the relative affluence of a property. This finding is supported by studies examining data-sets of burgled houses. Studies of this nature can be particularly useful as they will include characteristics of burglaries where the perpetrator has not been caught and are usually compared to non-burgled houses or features of attempted burglaries e.g. Bernasco 
\& Luykx, 2003; Bernasco \& Nieuwbeerta, 2005; Brantingham \& Brantingham, 2004; Brown \& Altman, 1981; Coupe \& Blake, 2006). Features appraised include the property's decor and items of value that can be seen both inside and within its garden (size, decor, furniture), and the vehicles parked outside or in the driveway. This appraisal, coupled with access considerations, such as whether the property is detached or semi-detached allowing access at the sides and back (allowing further appraisal of the property and greater opportunities to both enter and escape) and/or increased cover by vegetation or out-buildings (Bernasco \& Nieuwbeerta, 2005; Garcia-Retamero \& Dhami, 2009; Nee \& Taylor, 2000), might render the target highly sought after. Brown and Altman (1981), supported more recently by Clare, Fernandez and Morgan (2009), noted that non-burgled homes in the vicinity of burgled ones had more 'symbolic' barriers (e.g. personalized signage), actual barriers (fences/gates) and fewer public access signs near the house. They were also more visible from neighbors' houses.

It is essential to emphasize the 'relative' aspect of this process. Despite burglars' protestations that they do not steal 'from their own' and always target properties of more affluent members of their society, time and again this has been shown to be untrue (see the Crime Survey of England and Wales (2013) for high levels of burgled social housing, with many victims uninsured) and this is supported by many interview studies (Budd, 1999; Maguire \& Bennett, 1982; Nee \& Taylor, 1988; and Shover, 1996). The increased familiarity of the environment closer to home (which have allowing richer schemas to build up associated with the area and particular housing), would also explain the victimization of properties with poorer market value. Richer schematic knowledge of particular types of housing may also explain the high level of repeat burglaries in general (Pease, 1998). 


\subsection{Is the property occupied?}

Evidence from a variety of sources strongly suggests that most burglars generally prefer an unoccupied target (Coupe \& Blake, 2006; Cromwell et al, 1991; Hearndon \& Magill, 2004: Nee \& Taylor, 2000; Maguire \& Bennett, 1982; Wright \& Decker, 1994) though in all cases bar Wright \& Decker (1994) burglars said they had entered occupied properties if no other target was appropriate and the occupants were asleep. Maguire \& Bennett's (1982) participants stated that they 'knew from experience' or 'had a feel for' whether a house was occupied or not (p. 84). Having assessed cues such as lighting (if dark) and signs of movement within the property, cars outside (Snook et al, 2011), windows open etc. burglars will often knock on the front door, if not too exposed to passers-by, with a 'ruse' story if the door is answered (Wright \& Decker, 1994) or assess occupancy more thoroughly from the rear of the property (Nee \& Taylor, 1998, 2000). By and large, burglars report that they do not want to meet their victims, even when the house is occupied (Shover, 1996).

\subsection{How difficult is it to get in?}

Several aspects of the property to do with its security can attract or deter the burglar (it is important to re-iterate that all of these evaluations are done automatically and instantaneously as the perpetrator arrives in a vulnerable environment; they may appraise several properties simultaneously and very speedily). Tougher to open (legitimately or otherwise) windows, doors and locks will cause a nuisance to the burglar who will be deterred if an easier and equally lucrative target is available (Bennett \& Wright, 1986; Cromwell et al, 1991; Goodwin, 2007; Hearndon \& Magill, 2004; Maguire \& Bennett, 1982; Nee \& Taylor, 2000). Similarly, alarms and dogs are part of the list of 'conditional deterrents' which increase the aggravation factor for the burglar. In some samples, security issues are 
reported as the least problematic category for the burglar (Hearndon \& Magill, 2004;

Palmer, Holmes \& Hollin, 2002; Taylor \& Nee, 1988) and mentioned least often (Nee \& Meenaghan, 2006). In others, security issues are reportedly given most priority (Cromwell et al, 1991; Garcia-Retamero \& Dhami, 2009). Differences in these preferences amongst samples could be explained by Nee \& Taylor's (2000) finding that, when actually presented with visual targets, it is the combination of cues that matters rather than the types, and points to the dynamic nature of more naturalistic decision-making. There is no doubt that 'target hardening' and security technology has improved dramatically over the decades that research on burglary has been undertaken, but it relies on the vigilance of the humans that installed it to operate it correctly, which is often not the case. Around half of our sample of burglars in 2006 had noticed increased security measures taken by householders in recent years, but the most common method of entry to their most recent target had been through an open window or door (Nee \& Meenaghan, 2006) ) $^{\mathrm{ii}}$ If necessary, most dogs can be dealt with (Cromwell et al, 1991, Nee \& Taylor, 1988) and alarms can actually be a motivating factor for burglars especially if the property is the only one to have an alarm in the vicinity (Nee \& Taylor, 1988; 2000; Taylor \& Nee, 1988) indicating the presence of valuable items within or of previous burglaries which will rouse the burglar's interest (and many alarms are often not activated). One of the most recent studies, comparing expert and novice burglars, noted that experts were rarely deterred by the security features of the property (Clare, 2011) indicating greater levels of skills and (importantly) greater self-efficacy in the expert burglar. While increased security may be a contributory factor to the down turn in the number of burglaries reported over recent years, it is important to note that this may have helped to displace crime onto poorer neighborhoods. In both the USA and UK in recent 
years, burglary of poorer, uninsured and unprotected housing, has increased dramatically (Bureau of Justice Statistics (BJS), 2013; CSEW, 2013).

\subsection{Temporal aspects}

A large study in 10 states of the USA (D'Allesio, Eitle \& Stolenzburg, 2012) noted a split at around 50:50 between daylight and darkness burglaries, indicating that crimes occur under both conditions. In a study of 6,000 burglary incidents in the UK, Coupe and Blake (2006) noted that to some extent more experienced burglars preferred the cover of darkness, focusing on townhouses (low cover at front), often with sleeping occupants, and entering at the rear of the property. In the daytime, more separated (expensive) housing with cover at the front and lower occupancy was most popular, alleviating some of the risks of being seen. These studies broadly concur with findings from large victimization studies in the US and UK (BJS, 2013; CSEW, 2013) though it should be stressed that like studies of the characteristics of burgled homes, they do not distinguish between levels of expertise in the perpetrators; unlike most offender studies. They do, however, point to clear choices made; choices that may vary between and within the burglar, depending on the environment presented and learned strategies.

\subsection{Substance misuse}

Not surprisingly, given the complex association between substance misuse and acquisitive crime (Nee \& loannou, forthcoming) many offenders in the above studies had substance dependencies, most notably in the samples of Clare (2011), Cromwell et al (1991) and Wright and Decker (1994) $)^{\mathrm{iii}}$ where heavy drug use was prominent. Interestingly however, as found in Bennett's early study of the management of opioid use amongst users 
(Bennett, 1986), offenders in these studies were able to manage their addiction to an extent that it did not appear to interfere notably with their expertise and cognitive processing in the commission of the burglary.

Pulling this section together, all of these examples of environmental evaluation, as well as earlier reference to pre-conscious scanning on the journey to crime, seem to represent clear evidence for the stage (3) of the Nee and Ward (this issue) model of dysfunctional expertise. One can see how the repeated practice and reward associated with undertaking numerous burglaries would facilitate the development of dense, complex and inter-connected schemas, which over time and experience will be instantly activated in certain criminogenic situations, in a cognitively efficient way. The ever-increasing exemplars stored in these schemas, alongside rules of thumb and heuristics will automatically drive how the offender cognitively and emotionally responds to the given situation. This in turn will guide Stage 4, the automatic 'expert-action' phase in which compensatory behavioral scripts are played out during target entry and commission of the crime, as follows.

\section{Target entry and commission of the crime}

Once the target has been chosen, features at the scene of the crime (such as how much cover there is at the front, whether there is side and/or rear access and/or darkness) will determine whether the property is entered from the front, side or back. Most experienced burglars in studies over the years, and certainly those in our experimental work using maps and slides ideally preferred to be able to explore targets and enter from the rear if this was possible (Nee \& Taylor, 2000) and this was witnessed in our most recent study (Nee, White, Woolford, Pascu, Barker \& Wainwright, in press) in which all participants with burglary expertise entered at the rear while novices (students) entered the very exposed 
front of the house. Recent victimization figures suggest that the front entrance has been used somewhat more commonly in recent years (CSEW, 2013) but this may be a feature of the fact that less affluent properties are burgled more often now. Small crowbars (jemmybars) and screwdrivers are the most common tools used to pry open windows and doors (Hearndon \& Magill, 2004; Nee \& Taylor, 1988; 2000) and, as noted earlier, while security features are more common, burglars say there is usually a relatively vulnerable window or door (Hearndon \& Magill, 2004; Nee \& Meenaghan, 2006; Nee \& Taylor, 2000; Palmer et al, 2002); which interestingly was also the case several decades ago (Winchester \& Jackson, 1982).

In comparison to target selection, very little work has centered on what burglars do once they are inside the property. Three studies stand out: Nee and Meenaghan (2006, 50 semi-structured interviews with experienced convicted offenders); Nee et al (in press, observations of six experienced ex-burglars undertaking a burglary in a real house and a computer simulated house in comparison with a control group of students); and Wright and Decker (1994, ethnographic interviews with 105 active burglars at the scenes of recent crimes). Further, in an interview study focusing on crime prevention issues, Hearndon and Magill (2004) included a brief assessment of behavior within the property with their 71 experienced convicted offenders, and similarly Clare's (2011) work (interviews with 53 expert and 53 novice burglars) also gives insights into perceptual and procedural expertise in the choice of items stolen once inside the dwelling.

As the burglar begins the burglary, he is likely to use the tried and tested behavioral formula that has worked in the past. This script will have been triggered by his schematic recognition of cues denoting a successful burglary on the outside of the property: 
'After so many years you know where you're heading straight away...senses on overdrive.' (Nee \& Meenaghan, 2006).

In accordance with the more efficient routes used to appraise the general locale outside, burglars will embark on a habitual search - a hybrid of what has worked in the past, yielding highest gains at lowest risk (i.e. allowing them to get out of the property as quickly as possible (Nee \& Meenaghan, 2006; Nee et al, under review; Wright \& Decker, 1994).

'The search becomes a natural instinct, like a military operation, becomes routine to concentrate on what's going on around you and where to find things. Most concentration is on the risk of someone coming back - search is natural.' (Nee \& Meenaghan, 2006).

More familiar interior layouts, or indeed properties they have burgled before, will facilitate this process and this is surely a contributing factor to repeat victimization, alongside the knowledge that sought after goods have been replaced (Palmer et al, 2002; Pease, 1998). The more systematic routes taken by experts are reflected in the mainstream literature on wayfinding expertise in which those more familiar with the layouts of particular environments adopt the 'route skeleton' heuristic when searching for a goal (Kuipurs, Tecuci \& Stankiewicz, 2003). Rather than the haphazard, random wanderings of the novice, the expert wayfinder tends to make a more efficient search, deviating from a central pathway (or spine).

In the studies above, burglars have most commonly aimed for the main bedroom first, then other adult bedrooms before a quick search of the downstairs (Nee \& Meenaghan, 2006; Nee et al, in press; Wright \& Decker, 1994). Whilst the search is 
undertaken, Clare (2011) noted that expert burglars had superior recognition of higher value articles. For instance, they avoided taking electronic goods that would age very quickly and aimed for smaller, more portable items such as jewelry, drugs, smaller electronic items and cash, than their less proficient counterparts. This is supported by Nee et al.'s (in press) observation that experienced ex-offenders undertaking mock burglaries chose fewer, more valuable items. They spent significantly more time in higher value areas of the property and used more systematic routes than the control group of non-offenders. The findings regarding items taken concurs with both British and US-based victimization surveys indicating a preference in recent years for more portable electronic goods, jewelry, cash, drugs and small personal items (handbags, briefcases and wallets) which yield a dramatically higher pay-out once passed on, than a decade ago, even when adjusted for value for comparison purposes (BJS, 2013; CSEW, 2013). Interestingly, supporting Maguire and Bennett's (1982) findings over 20 years ago and fitting with an understanding of procedural skill and its relationship to risk, these surveys indicate that more individual and identifiable goods such as silver, china, antiques and art are still rarely taken as they are too risky to get rid of, and hence indicate strategies to avoid detection post-offense.

All-in-all, despite fewer studies on the burglar's navigation and search of the property, there is promising evidence in general and in relation to comparison groups, that he is demonstrating the speed and efficiency of the expert, relying on denser schemas, allowing him to multitask (e.g. listening for home-comers with his under-utilized working memory (Nee \& Meenaghan, 2006)) and acting more-or-less automatically.

\section{What happens after the crime}


We know almost nothing about the cognitive and emotional processes that occur in the hours after the crime, aside from how stolen goods are disposed of. It seems reasonable to suggest that offenders continue to use superior schematic knowledge to exit the property and to get away from the general location of the burglary, be it on foot or by vehicle. We also know that uppermost in the offender's mind is a need to convert stolen goods into disposable cash as soon as possible (Wright \& Decker, 1994); this is usually done within hours and mostly within a day of the burglary (Ferrante \& Clare, 2006). Unsurprisingly, burglars take some care regarding whom they pass on their goods onto. Receivers are mostly drug dealers, fences, family and friends and dishonest pawnbrokers/second hand goods shops (Ferrante \& Clare, 2006; Wright \& Decker, 1994). Few keep any goods themselves (except for occasionally keeping guns and ostentatious jewelry in Wright \& Decker's sample) and the majority make little effort to get the best price for their goods, accepting any offer that will satisfy their immediate need (usually around a third of market value (Clare,2011)). In his study on expert versus novice burglars however, Clare (2011) noted that experts were more discriminating regarding whom they sold to, rarely using family and friends, and were more prepared to bargain to get an acceptable price. One can also surmise that, given that burglars rarely report getting caught at the scene of the crime, the chaotic lifestyle outside of the offending domain described by many researchers (Maguire \& Bennett, 1982; Shover, 1973; Wright \& Decker, 1994) still ensues. Clare's (2011) work also suggests that ways of avoiding detection after the offense may be less welldeveloped in many offenders than the superior skill shown in undertaking the offense noted in so many studies of burglars and burglary. No studies of burglars, however, have looked at the 'reflection stage' after the offense described in Bourke, Ward and Rose's (2012) study of sex offenders and this certainly needs to be done. 
In terms of emotion experienced following the completion of a crime, Katz (1988) has noted the euphoria of being thrilled after acquisitive crime, suggesting stealing is more to do with escaping the shame of being caught than with the material acquisition. The excitement and emotion associated with undertaking a burglary has been played down in comparison to other contributory factors in the early part of the decision chain (see early part of this article for several studies with evidence of this). Despite this, a considerable number of Wright \& Decker's (1994) sample reported feeling intense elation following the completion of a burglary. In our own recent observations of ex-burglars undertaking mock burglaries (Nee et al, in press), one participant reported that it took three hours for him to 'come down from the buzz' of being placed in that environment again. It would be unwise not to explore in more depth the cognitions and emotions involved in the hours and days after the crime in future research. It is true that the offense has already occurred, but clearer information about the level of reward, a sense of self-efficacy and possible anxiety and remorse felt, may be crucial parts of the explanatory picture. Such research will also be helpful in planning future interventions with persistent offenders and suggesting ways of interrupting the processes in future journeys to crime (Van Gelder et al, 2014).

\section{Implications for crime prevention and future directions.}

By looking at the decision-chain and behavior of the burglar from an initial decision to commission of an offence to post crime, this review aimed to highlight what we have learned about the expertise of the offender from decades of research. Notwithstanding individual preferences at the scene of the crime (often governed by changing cues in the environment), it is remarkable how consistent many features of these studies are (regarding the sequential nature of the decision-chain; the nature of cues used, and the nature of the 
search inside the property) despite varied samples from different ethnic backgrounds, using a range of methodologies, in different countries across the world (Nee, 2010). This special issue, and this article on burglary in particular have aimed to elucidate more clearly what evidence we have for the core features of expertise in offenders. The studies above, especially those with comparison groups of novices in the form of householders, police officers, students and other offenders strongly suggest the use of: superior, richer and more interconnected schemas (allowing instant, compensatory recognition and decisions about cues in the environment); automaticity (evidenced in the lack of deliberative thought described and the swifter, more efficient commission of the burglary); selective attention and situational awareness (the superior knowledge of cues that are particularly meaningful to carrying out an effective burglary, in comparison to other groups, and the ability to selectively prioritize these); and multitasking (the ability to do the burglary on 'automatic pilot' while consciously utilizing working memory to listen for home-comers).

Our model of dysfunctional expertise (Nee \& Ward, this issue) was developed to account for these findings (plus data/observations from other types of offenders) and we turned to research and theories of mainstream cognitive science to assist in this process. We hope that the model will be a useful explanatory tool in future research as we aim to much more clearly elucidate decision-making and other contributory processes that surround the commission of crime. The model appears to account for what we know from empirical studies of burglary in a useful and robust way, but there is a considerable amount to be learnt, using more precise methods, particularly in relation to before and after the crime and as a consequence the model may need augmenting. For instance, future research could give us a clearer picture about the levels of consciousness involved in decision- 
making, as well as understanding more about levels of expertise within offenders. As well as informing more effective interventions, this approach could improve understanding by adding a crucial but missing aspect to, for instance, crime linkage work that analyses aspects of the criminogenic environment (Bernasco \& Nieuwbeerta, 2005; Mawby, 2001; Tonkin, Bull, \& Santilla, 2012; Woodham, Hollins \& Bull, 2008) and victimization studies that do not differentiate between levels of proficiency in offenders.

\subsection{Crime prevention implications}

Findings from the mainstream expertise literature as it stands can guide us in the planning of future research to reduce opportunities for crime in the environment. As noted in the introductory article of this special issue, we need to capitalize on the fact that burglars are expecting a familiar environment, especially once they have broken into a dwelling, an environment in which their routine, expert behavior functions well without having to think about it. Although the crime is already happening, sudden unexpected events could well result in the offender aborting the crime due to cognitive overload (Woollett \& Maguire, 2010) and the resulting anxiety. Both Wright \& Decker (1994) and Nee et al (in press) have noted the unexploited potential for utilizing crime prevention techniques once the offense is underway). The low clear-up rate indicates that very few burglars are caught in the act, and this may make these techniques especially powerful. A variety of strategies could be tested during simulated crimes in both natural and computer simulated environments that not only present the experienced burglar with an unexpected layout, noise or event, but also capitalize on the inflexibility and over-confidence associated with heightened expertise (see Nee \& Ward, this issue). Evidence is accruing that simulations can replicate real behavior to an acceptable level in crime-focused work (Nee et 
al, in press; Park et al, 2012; Slater et al, 2013). This method is also arguably more methodologically sound, more ethical and more manageable than taking offenders back to the scenes of recent crimes as cognition and emotions that are aroused as a result of the research can be discussed and addressed in a more controlled environment. Additionally, Cromwell et al (1991) noted that burglars were less 'rationally reconstructive' and reacted in a more naturalistic way when presented with a 'real' criminogenic environment.

Finding ways to make the actual commission of the crime less rewarding (or even mildly aversive - such as enhancing awareness of the impact on victims as the burglary is undertaken) may be one way to interrupt the less conscious aspects of the journey to crime, or even enhance the consciousness of the pre-conscious scanning stage, or the journey to crime (similar to Devine's (1989) notion of replacing automatic, prejudicial stereotypes with 'fairness' ones). Indeed, simulations may not just be a tool for research but also potentially for rehabilitation, as Van Gelder (2013) has successfully shown.

Our first challenge is to undertake research using a variety of methods (interview, experiments, simulations and observations, involving offenders and a variety of comparison groups including offenders without expertise in the area of interest (Logie et al, 1992). This should enable us to understand more clearly the entire decision-making process. Preconscious environmental scanning, the journey to crime and post-crime processes are aspects of burglary that we know very little about. Our aim should then be to prevent dysfunctional expertise accruing in individuals. We know that expert burglars begin offending at a younger age, are the most motivated and the least likely to be deterred by situational crime prevention strategies than their less proficient counterparts (Clare, 2011). As always, the reduction of crime needs to have a three-pronged approach: preventing 
young people at risk of offending beginning their criminal 'career', interventions with those

already involved, and reduction of opportunity in the environment (Pease, 2002). It is highly

likely in my view, that an expertise model such as the one we are working towards in this

special issue, will be a valuable tool in addressing all three aspects.

\section{References}

Bennett, T. (1986). A decision-making approach to opioid use. In D. Cornish, \& R. Clarke (Eds). The reasoning criminal: rational choice perspectives on offending. 83-98, New York: Spinger-Verlag.

Bennett, T. \&. Wright. R. (1984). Burglars on burglary : prevention and the offender. Aldershot: Gower.

Bernasco, W., \& Luykx, F. (2003). Effects of attractiveness, opportunity and accessibility to burglars on residential burglary rates of urban neighborhoods. Criminology, 41, 3, 981-1002.

Bernasco, W., \& Nieuwbeerta, P. (2005). How do residential burglars select target areas? A new approach to the analysis of criminal location choice. British Journal of Criminology, 45, 296-315.

Bourke, P., Ward, T., \& Rose, C. (2012). Expertise and sexual offending: A preliminary empirical model. Journal of Interpersonal Violence, 27(12), 2391-2414 doi:10.1177/0886260511433513

Brantingham, P. J., \& Brantingham, P. L. (1975a). The spatial patterning of burglary. The Howard Journal of Criminal Justice, 14(2), 11-23. doi: 10.1111/j.14682311.1975.tb00297.x

Brantingham, P. L., \& Brantingham, P. J. (1975b). Residential burglary and urban form. Urban Studies, 12(3), 273-284. doi: 10.1080/00420987520080531

Brantingham, P. J., \& Brantingham, P. L. (1991). Environmental Criminology. Illinois: Waveland Press.

Brantingham, P. L., \& Brantingham, P. J. (1993). Environment, routine, \& situation: toward a pattern theory of crime. In Ronald V. Clarke \& Marcus Felson (Eds.) From Routine Activity \& Rational Choice: Advances in Criminological Theory. (Vol. 5, pp. 259-294). New Jersey: Transaction Publishers.

Brantingham, P. L., \& Brantingham, P. J. (2004). Environment, routine, \& situation: toward a pattern theory of crime. In Ronald V. Clarke \& Marcus Felson (Eds.) From Routine Activity \& Rational Choice: Advances in Criminological Theory. (Vol. 5, pp. 259-294). New Jersey: Transaction Publishers

Brown, B.B., \& Altman, I. (1981). Territoriality and residential crime: A conceptual framework. In P.J. Brantingham \& P.L. Brantingham (Eds.), Environmental criminology, 1, 55-76.

Budd, T. (1999). Burglary of Domestic Dwellings: Findings from the British Crime Survey. Home Office Statistical Bulletin 4/99. London: Home Office.

Bullock, K., Chowdhury, R. Hollings, P. (2009) Public Concerns about Organised Crime. Home Office Research Report 16. London: Home Office. 
Bureau of Justice Statistics (2013). Special report: Household burglary 1994-2011. NCJ 241754. Office of Justice Programs.

Chartrand, T., \&. Bargh, J. (2002). Nonconscious motivations: Their activation, operation, and consequences: American Psychological Association.

Chi, M. (2006). Two approaches to the study of experts' characteristics. In K. Ericsson, N. Charness, P. Feltovich \& R. Hoffman (Eds.), The Cambridge handbook of expertise and expert performance (pp. 21-30). Cambridge: Cambridge.

Clare, J. (2011). Examination of systematic variations in burglars' domain-specific perceptual and procedural skills. Psychology, Crime \& Law, 17(3), 199-214. doi: 10.1080/10683160903025810

Clarke, R. V. G. \& Hope, T. (1984). (Eds.), Coping with burglary. Boston: KluwerNijhoff.

Cohen, L. E., \& Felson, M. (1979). Social Change and Crime Rate Trends: A Routine Activity Approach. American Sociological Review, 44(4), 588-608. doi: 10.2307/2094589

Cornish, D.B., \& Clarke, R.V.G. (1986). (Eds.) The reasoning criminal: rational choice perspectives on offending, 1-13, New York: Spinger-Verlag.

Coupe, T., \& Blake, L. (2006). Daylight and darkness targeting strategies and the risks of being seen at residential burglaries. Criminology, 44, 431-464. doi: 10.1111/j.17459125.2006.00054.x

Crime Survey of England and Wales (May 2013) retrieved from http://www.ons.gov.uk/ons/rel/crime-stats/crime-statistics/focus-on-propertycrime--

Cromwell, P., Olson, J. \& Avary, D. (1991). Breaking and entering: an ethnographic analysis of burglary. Newbury Park: Sage.

D’Alessio, S. Eitle, D. \& Stolzenberg, L. (2012). Unemployment, Guardianship,and Weekday Residential Burglary. Justice Quarterly 29, 919-32.

Devine, P. (1989). Stereotypes and prejudice: their automatic and controlled components. Journal of Personality and Social Psychology, 56, 5-18. 10.1037/0022-3514.56.1.5

Duckworth, K.L., Bargh, J.A., Garcia, M., \& Chaiken, S. (2002). The automatic evaluation of novel stimuli. Psychological Science, 6, 515-519.

Elffers, H., Reynald, D., Averdijk, M., Bernasco, W. and Block, R. (2008). Modelling crime flow between neighbourhoods in terms of distance and of intervening opportunities. Crime Prevention and Community Safety. 10(2), 85-96.

Ericsson, K. A. (2006). An introduction to the Cambridge handbook of expertise and expert performance: its development, organisation and content. In K. Ericsson, N. Charness, P. Feltovich \& R. Hoffman (Eds.), The Cambridge handbook of expertise and expert performance (pp. 3-20). Cambridge: Cambridge University Press.

Ericsson, K. A., Charness, N., Feltovich, P. J., \& Hoffman, R. R. (2006). The Cambridge handbook of expertise and expert performance: Cambridge University Press.

Ericsson, K. A. \& Kintsch, W. (1995). Long-term working memory. Psychological Review. 102, 211-245. 10.1037/0033-295X.102.2.211

Ericsson, K. A., Krampe, R. \& Tesch-Romer, C. (1993). The Role of Deliberate Practice in the Acquisition of Expert Performance. Psychological Review, 100, 363-406.

Federal Bureau of Investigations (2009). Retrieved from https://www2.fbi.gov/ucr/cius2009/offenses/clearances/index.html\#figure

Felson, M. (1998). Crime and everyday life. First edition. California: Thousand Oaks.

Felson, M. \& Boba, R. (2010). Crime and everyday life. Fourth edition. California: Thousand Oaks 
Ferrante, A., \& Clare, J. (2006). 'Known' burglars and the stolen goods market in western Australia (Research Report). Perth: Office of Crime Prevention, Western Australian Department of Premier and Cabinet.

Garcia-Retamero, R., \& Dhami, M. K. (2009). Take-the-best in expert-novice decision strategies for residential burglary. Psychonomic Bulletin \& Review, 16, 163-169. doi:10.3758/PBR.16.1.163

Gilovich, T. (1981).Seeing the past in the present: The effect of associations to familiar events on judgments and decisions. Journal of Personality and Social Psychology, 40, 797-808.

Goodwin, V. (2007). Burglary in Tasmania: the offender's perspective. Briefing paper No 4. Tasmania: National Institute of Law Enforcement Studies.

Hamman, S. (2001). Cognitive and neural mechanisms of emotional memory. Trends in Cognitive Science, 5, 394-403.

Heal, K. \& Laycock, G. (1986). Situational crime prevention: from theory into practice. London: Her Majesty's Stationery Office.

Hearndon, I., \& Magill, C. (2005), Decision-Making by House Burglars: Offenders' Perspectives. Home Office Research Findings No. 249. London: Home Office.

Homel, R., Macintyre, S. and Wortley, R. (2014). How burglars decide on targets: a computer-based scenario approach. In B. LeClerc \& R.Wortley (Eds.). Cognition and crime: offender decision making and script analyses. Oxford: Routledge.

Jacques, S., Wright, R., \& Allen, A. (2014). Drug dealers, retaliation, and deterrence. International Journal of Drug Policy.

Katz, J. (1988). Seductions of Crime: moral and sensual attractions in doing evil (5th printing ed.). New York: Basic Books. ISBN 9780465076154

Kuipers, B. J., Tecuci, D. G. \& Stankiewicz, B. J. (2003). The skeleton in the cognitive map: a computational and empirical exploration. Environment \& Behavior, 35, (1):80-106

Logie, R.H., Wright, R.T. \& Decker, S. (1992), Recognition memory performance and residential burglary, Applied Cognitive Psychology, 6:109-123.

10.1002/acp.2350060203

Lurigio, A. J. (1987). Are all victims alike? The adverse, generalized, and differential impact of crime. Crime \& Delinquency, 33, 452-467. doi:10.1177/0011128787033004003

Maguire, M., \& Bennett, T. (1982). Burglary in a dwelling : the offence, the offender and the victim. London: Heinemann.

Mawby, R. (2001). Burglary. Devon: Willan Publishing.

Mayhew, P. M., Clarke, R. V. G., Sturman, A, \& Hough, J.M. (1976). Crime as Opportunity. Home Office Research Study, No 34. H.M.S.O, London.

Mullins, C. \& Wright, R. (2003). Gender, social networks, and residential burglary. Criminology, 41, 1601-1628.

Nee, C. (2010). Research on residential burglary: ways of improving validity and participants' recall when gathering data. In W. Bernasco (Ed.). Offenders on Offending: learning about crime from criminals. Devon: Willan Press.

Nee, C. \& loannou, S. (forthcoming). What have neuroscientific approaches to research taught us about acquisitive offenders? In R. Mann \& A. Beech (Eds.) Handbook of Forensic Neuroscience.

Nee, C., \& Meenaghan, A. (2006). Expert decision-making in burglars. British Journal of Criminology, 46(5), 935-949. doi: 10.1093/bjc/az1013

Nee, C., \& Taylor, M. (2000). Examining burglars' target selection: Interview, experiment or 
ethnomethodology? Psychology, Crime \& Law, 6(1), 45-59. doi:

10.1080/10683160008410831

Nee, C. \& Taylor, M. (1988). Residential burglary in the Republic of Ireland: a situational perspective. Howard Journal. 27(2), 105-116.

Nee, C., \& Ward, T. (this issue). Introduction: Review of expertise and its general implications for correctional psychology and criminology. Aggression and Violent Behavior.

Nee, C., White, M., Woolford, K., Pascu, T., Barker, L. \& Wainwright, L. (in press). New methods for examining expertise in burglars in natural and simulated environments: preliminary findings. Psychology, Crime and Law.

Newman, O. (1972). Defensible space: crime prevention through urban design. MacMillan: New York.

Osgood, D. W., Wayne, D., Wilson, J., Bachman, J., O'Malley P. \&. Johnston, L. (1996). Routine Activities and Individual Deviant Behavior. Encyclopedia of Criminological Theory. SAGE Publications, Inc. Thousand Oaks, CA: SAGE Publications, Inc.

Palmer, E.J., Holmes, A. And Hollin, C.R. (2002). investigating burglars' decisions: factors influencing target choice, method of entry, reasons for offending, repeat victimisation of a property and victim awareness. Security Journal, 7-18.

Park, A., Clare, J., Spicer, V., Brantingham, P., Calvert, T. \& Jenion, G. (2012). Examining context-specific perceptions of risk: exploring the utility of 'human-in-the-loop' simulation models for criminology. Journal of experimental criminology, 8, 29-47. 10.1007/s11292-011-9132x

Pease, K. (1998). Repeat Victimisation: Taking Stock. Crime detection and Prevention Series Paper 90. London: Home Office.

Pease, K. (2002). Crime reduction. In M. Maguire \& R.Morgan (Eds.). Oxford handbook of criminology. $3^{\text {rd }}$ Edition. Oxford: Oxford University Press.

Rengert, G. F., \& Wasilchick, J. (1985). Suburban burglary: a time and a place for everything. Springfield, Illinois: C.C. Thomas.

Rengert, G. F., \& Wasilchick, J. (2000). Suburban burglary: a tale of two suburbs. Chicago: Thomas.

Reppetto, T. A. (1974). Residential crime. Cambridge, Mass.: Ballinger.

Scarr, H. A. (1973). Patterns of burglary. United States of America: U.S. Government Printing Office.

Slater, M., Rovira, A., Southern, R., Swapp, D., Zhang, J. J., et al. (2013) Bystander responses to a violent incident in an immersive virtual environment. PLOS ONE 8(1): e52766. doi:10.1371/journal.pone.0052766.

Sherman, L., Gartin, P. \&amp; Buerger, M. (2006). Hot Spots of Predatory Crime: routine activities and the criminology of place. Criminology, 27(1), 27-56. doi:

10.1111/j.1745-9125.1989.tb00862.x

Shover, N. (1973). The Social Organization of Burglary. Social Problems, 4, 499-514.

Shover, N. (1996). Great Pretenders: Pursuits And Careers Of Persistent Thieves. Colorado: Westview Press.

Shover, N., \& Honaker, D. (1992). The Socially Bounded Decision Making of Persistent Property Offenders. Howard Journal of Criminal Justice, 31(4), 276-294.

Smith, K., Talyor, P. \& Elkin, M. (2013). Crimes detected in England and Wales 2012/13. Home Office Statistical Bulletin 02:13. London: Home Office. 
Snook, B., Dhami, M. K., \& Kavanagh, J. (2011). Simply criminal: Predicting burglars' occupancy decisions with a simple heuristic. Law and Human Behavior, 35, 316-326.

Taylor, M. \& Nee, C. (1988). The role of cues in simulated residential burglary: a preliminary investigation. British Journal of Criminology, 28, 396-401.

Tonkin, M., Bull, R., \& Santtila, P. (2012). The linking of burglary crimes using offender behavior: Testing research cross-nationally and exploring methodology. Legal and Criminological Psychology, 17, 276-293.

Tseloni, A., Mailley, J., Farrell, G., \& Tilley, N. Exploring the international decline in crime rates. European Journal of Criminology, 7, 375-394. doi: http://dx.doi.org/10.1177/1477370810367014

Van Gelder, J.L., Hershfield, H. \& Nordrgen, L. (2013). Vividness of the future self reduces delinquency. Psychological Science, 24, 974-980.

Van Gelder, J. L., Elffers, H., \& Nagin, D. S. R., D. (2013). Affect and cognition in criminal decision making. Oxford: Routledge.

Waller, I., \& Okihiro, N. R. (1978). Burglary: the victim and the public: Published in association with the Centre of Criminology, University of Toronto Press.

Ward, T. \& Nee, C. (2009). Surfaces and depths: evaluating the theoretical assumptions of cognitive skills programmes. Psychology, Crime and Law (special edition on Offender Cognition and Emotion), 15, 165-182.

Warr, M. (2000). Fear of crime in the United States: avenues for research and policy. Criminal Justice, 4: 451-489.

Winchester, S. \& Jackson, S. (1982). Residential burglary: the limits of prevention. London: HMSO.

Woodhams, J., Hollin, C., and Bull, R. (2008). Incorporating context in linking crimes: An exploratory study of situational similarity and if-then contingencies. Journal of Investigative Psychology and Offender Profiling, 5, 1-23.

Woollett, K. \& Maguire, E. (2010). The effect of navigational expertise on wayfinding in new environments. Journal of Environmental Psychology, 30, 565-573.

Wright, R. T., \& Decker, S. H. (1994). Burglars on the Job: Streetlife and Residential Break-Ins. Boston: Northeastern University Press.

Wright, R., \& Logie,R. (1988) How young burglars choose targets. The Howard Journal of Criminal Justice 27, 92-104.

Wright, R.T., Logie, R.H. \& Decker, S.H. (1995). Criminal expertise and offender decision making: an experimental study of the target selection process in residential burglary. Journal of Research in Crime and Delinquency, 32, 39-53. 10.1177/0022427895032001002

\footnotetext{
'Burglary is a notably male occupation, but for an unusual insight into the role of women in the undertaking of the crime, see Mullins \&Wright (2003).

ii And this is repeatedly the case in the BBC TV series 'Beat the Burglar' in which ex-burglars victimise properties while householders observe in order to learn crime prevention.
} 
iii The increased substance misuse in the latter two samples may have been a feature of the fact that they were active offenders at large. 